\title{
Article
}

\section{Locally expressed CTLA4-Ig in a pancreatic beta-cell line suppresses accelerated graft rejection response induced by donor-specific transfusion}

\author{
F. Kimura ${ }^{1,2}$, M. Gotoh ${ }^{1,4}$, T. Tanaka ${ }^{1}$, Z. Luo ${ }^{1}$, J. Miyazaki $^{3}$, T. Uede ${ }^{5}$ M. Monden ${ }^{2}$, M. Miyasaka ${ }^{1}$ \\ ${ }^{1}$ Molecular and Cellular Recognition, ${ }^{2}$ Department of Surgery and Clinical Oncology, ${ }^{3}$ Department of Nutrition \\ and Physiological Chemistry, Osaka University Graduate School of Medicine, Osaka, Japan \\ ${ }^{4}$ First Department of Surgery, Fukushima Medical University, Fukushima, Japan \\ ${ }^{5}$ Section of Immunopathogenesis, Institute of Immunological Science, Hokkaido University, Sapporo, Japan
}

\section{Abstract}

Aims/hypothesis. This study examined whether locally expressed CTLA4-Ig can suppress the accelerated islet allograft rejection that is induced by donor-specific transfusion.

Methods. CTLA4-Ig-transfected or parental MIN6 cells were transplanted subcutaneously into the right flank of streptozotocin-induced diabetic $\mathrm{C} 3 \mathrm{H} / \mathrm{Hej}$ mice with or without donor-specific transfusion. For donor-specific transfusion, spleen cells from C57BL/6 mice were injected i.v. at the time of transplantation. In other experiments, CTLA4-Ig-transfected and parental MIN6 cells were transplanted separately into each flank, together with donor-specific transfusion. Rejection was defined as a blood glucose concentration of more than $300 \mathrm{mg} / \mathrm{dl}$ in two consecutive measurements, and graft survival was confirmed by hyperglycaemia after the grafts were removed. The effect of an anti-CTLA4 antibody on the survival of CTLA4-Ig-transfected MIN6 cells was also examined.
Results. In 7 of 12 donor-specific transfusion sensitised mice, CTLA4-Ig-transfected MIN6 cells remained viable 20 days after grafting, whereas all parental MIN6 cells $(n=10)$ were rejected promptly, within 14 days. The prolonged allograft survival was observed even in the absence of detectable levels of serum CTLA4-Ig, while the surviving allografts continued to produce CTLA4-Ig in situ. This protection was abrogated by an anti-CTLA4 antibody, but not by a control antibody. Furthermore, six animals that maintained normoglycaemia after the separate transplantation of parental and CTLA4-Ig-transfected MIN6 cells into each flank all showed abrupt hyperglycaemia after the CTLA4-Ig/MIN6 graft was removed, suggesting that this protection operated locally.

Conclusion/interpretation. A beta-cell line genetically engineered to secrete CTLA4-Ig can protect a graft locally from the alloimmune response induced by donorspecific transfusion. [Diabetologia (2002) 45:831-840]

Keywords: CTLA4-Ig, MIN6, transplantation, donorspecific transfusion, mouse
The insulin-secreting islets comprise only a small fraction of the whole pancreas $(\sim 1 \%)$; therefore, the

Received: 30 July 2001 / Revised: 11 February 2002

Published online: 25 May 2002

(C) Springer-Verlag 2002

Corresponding author: M. Gotoh, MD, First Department of Surgery, Fukushima Medical University, 1 Hikarigaoka, Fukushima 960-1295, Japan, e-mail: mgotoh@fmu.ac.jp Abbreviations: APC, Antigen-presenting cell; DST, donor-specific transfusion; $\mathrm{mAb}$, monoclonal antibody; MLR, mixed lymphocyte response; MST, mean survival time; STZ, steptozotocin transplantation of purified islets rather than the whole pancreas seems to be a reasonable approach to control metabolic dysfunction in patients with Type I (insulindependent) diabetes mellitus. Although the survival of vascularised pancreas allografts at one year has significantly improved following the introduction of $\mathrm{T}$ cellspecific immunosuppressants such as cyclosporin and FK506 [1], the survival of pancreatic islet grafts under the same immunosuppressive regimen is still under $30 \%$ one year after transplantation [2]. However, a current study reports that seven consecutive patients attained sustained insulin independence after pancreatic islet transplantation [3]. All these recipients were 
preuremic and given islets alone under steroid-free immunosuppressive regimen. It is still not known whether similar results can be obtained when islets are given together with a kidney allograft into a uremic patient with Type I diabetes because it has been shown that islet grafts are quite vulnerable to alloimmune response $[4,5]$.

We have previously shown in a rodent islet transplantation model that crude collagenase-digested islets obtained after separation in a Ficoll density gradient are highly immunogenic, and that the removal of contaminants such as lymph nodes and vascular and ductal tissues from the islets by handpicking markedly reduces the islet graft immunogenicity [5]. When transplanted to allogeneic recipient mice, some of the purified islet allografts survived indefinitely without immunosuppression [5]. On the other hand, when the purified islets and contaminants were transplanted together into the same renal subcapsular space or separately into the contralateral renal subcapsular spaces, the purified islet allografts were acutely rejected. These results suggest that purified islets are less immunogenic than crude preparations, but are vulnerable once an immune response is generated. Thus, blood transfusion [4] or simultaneous kidney allotransplantation, which has been carried out in most of previous islet recipients [1], might cause a systemic anti-donor response that would lead to the destruction of islet allografts.

We and others have shown that the site-specific delivery of immunosuppressive molecules could provide an alternative strategy to avoid the hazardous side effects of conventional immunosuppressants $[6,7,8,9]$. Various immunosuppressive molecules have been tested in a variety of transplantation models and need to be assessed for their effectiveness on graft prolongation. In one of the strategies examined, the blockade of co-stimulatory signals by immunosuppressive proteins has been shown to prolong allograft survival in various transplantation settings $[10,11]$. In T cell-mediated immunity, the full activation of naïve $T$ cells requires co-stimulatory signals generated by the ligation of CD28 on T cells with their receptor, B7-1/B7-2, on antigen-presenting cells (APCs) [12]. CTLA4, a homologue of $\mathrm{CD} 28$, when expressed on activated $\mathrm{T}$ cells, can bind B7-1/B7-2 with a higher affinity than CD28, and compete efficiently for B 7-1/B7-2, thereby blocking the co-stimulatory signals for $\mathrm{T}$ cells [13]. A chimeric fusion protein, CTLA4-Ig, which is composed of the extracellular region of CTLA4 and the Fc portion of IgG1, similarly blocks the CD28-mediated co-stimulatory pathways, and down-regulates the immune response in various experimental transplantation models. When administered systemically $[14,15,16$, 17] or expressed in engrafted tissues by gene transfer $[8,9,18]$, CTLA4-Ig prolongs graft survival, and occasionally induces graft-specific unresponsiveness. However, it has not yet been established whether the prolongation of graft survival is obtained by a local or systemic immunoregulatory mechanism.

In this study, we used the insulinoma cell line MIN6, which retains the physiological characteristics of pancreatic beta cells and secretes insulin in a glucose-dependent manner [19], to examine the effects of local CTLA4-Ig expression on beta-cell survival in diabetic recipient mice. To induce a systemic anti-donor response, we performed a donor-specific transfusion (DST) of spleen cells at the time of transplantation, which causes a dose-dependent accelerated rejection of purified islets [5].

Here we showed that MIN6 cells that were genetically engineered to produce CTLA4-Ig protected engrafted MIN6 cells locally, but did not protect MIN6 cells at a remote site, when an anti-donor response was generated by DST.

\section{Materials and methods}

Mice. Male 6- to 8-week-old $\mathrm{C} 3 \mathrm{H} / \mathrm{Hej}\left(\mathrm{H}-2^{\mathrm{k}}\right)$ and $\mathrm{C} 57 \mathrm{BL} / 6$ $\left(\mathrm{H}-2^{\mathrm{b}}\right)$ mice were purchased from Clea Japan (Osaka, Japan). Mice were reared in a specific pathogen-free environment at the Institute of Experimental Animal Sciences, Osaka University Graduate School of Medicine. C3H/Hej mice in which diabetes was induced with streptozotocin (STZ) (Sigma Chemical, St. Louis, Mo., USA) (300 mg/kg body) were used as recipients. The experimental protocol was approved by the Ethics Review Committee for Animal Experimentation of Osaka University Graduate School of Medicine.

Cell lines. A pancreatic beta-cell line (MIN6) was previously established from an insulinoma that had developed in a transgenic mouse (C57BL/6) expressing the SV40 T-antigen gene under the control of the human insulin-promoter [19]. The MIN6 cells were cultured in DMEM (Sigma Chemical, St. Louis, Mo., USA) supplemented with $25 \mathrm{mmol} / 1$ glucose, $15 \%$ heat-inactivated fetal calf serum (FCS) (Dainippon Pharmaceuticals, Osaka, Japan), $100 \mathrm{U} / \mathrm{ml}$ penicillin, $100 \mu \mathrm{g} / \mathrm{ml}$ streptomycin, $10 \mathrm{mmol} / \mathrm{l} \mathrm{HEPES}$, and $50 \mu \mathrm{mol} / 1$ 2-mercaptoethanol (Life Technologies, Carlsbad, Calif., USA). MIN6 cells were used at 15-20 passages. B7.1-transfected P815 cells [20], which were kindly donated by Dr. H. Yagita (Department of Immunology, Juntendo University School of Medicine, Tokyo, Japan) were cultured in RPMI 1640 medium supplemented with $10 \%$ heat-inactivated FCS, $10 \mathrm{mmol} / \mathrm{l} \mathrm{HEPES,} 2 \mathrm{mmol} / \mathrm{l}$ L-glutamine, $1 \mathrm{mmol} / \mathrm{l}$ sodium pyruvate, $100 \mathrm{U} / \mathrm{ml}$ penicillin, $100 \mu \mathrm{g} / \mathrm{ml}$ streptomycin, $0.1 \mathrm{mmol} / \mathrm{l}$ non-essential amino acids, and $50 \mu \mathrm{mol} / 12$-mercaptoethanol, as described previously [20]. Plasmid preparation. CTLA4-Ig consists of the extracellular portion of murine CTLA4 and the Fc portion of human IgG1, as previously described [21]. The cDNA fragment encoding CTLA4-Ig was excised from the expression vector CDM8CTLA4Ig. The ends were blunted and ligated with an EcoRI linker. The cDNA fragment was then inserted into the expression vector pCXN [22], which contains the chicken beta actin promoter and the neomycin phosphotransferase II gene, to generate the expression plasmid pCXN-CTLA4-Ig.

Transfection of COS7 cells with CTLA4-Ig. To obtain CTLA4Ig protein, COS7 cells were transfected with pCXN-CTLA4-Ig using a DEAE-dextran method [23] (Pharmacia Biotech, Uppsala, Sweden). The CTLA4-Ig protein was purified from se- 
rum-free conditioned medium by $50 \%$ saturated ammonium sulfate precipitation and protein G-Sepharose affinity chromatography (MAbTrapTMGII; Pharmacia Biotech). Purified CTLA4-Ig were separated by SDS-PAGE and quantitated by densitometry of Coomassie blue-stained gels.

Preparation of spleen cells. The spleen was aseptically removed and mechanically teased in $10 \mathrm{ml}$ of Hank's balanced salt solution containing $2 \% \mathrm{FCS}, 100 \mathrm{U} / \mathrm{ml}$ penicillin and $100 \mu \mathrm{g} / \mathrm{ml}$ streptomycin. Cell suspensions were filtered through $100-\mu$ mylon mesh, and then treated with $\mathrm{NH}_{4} \mathrm{Cl} /$ Tris buffer to remove red blood cells. Thereafter, cells were washed three times and prepared for DST in Hank's balanced salt solution.

Transfection of MIN6 cells with CTLA4-Ig. To generate stable transfectants, pCXN-CTLA4-Ig was transfected into MIN6 cells (passage 15) using Lipofectamin (Life Technologies). As a negative control, the $\mathrm{pCXN}$ vector without the CTLA4-Ig insert was transfected into MIN6 cells. Selection was begun 2 days after transfection by adding G418 (Sigma) to the media at $600 \mu \mathrm{g} / \mathrm{ml}$. Surviving colonies were cloned and screened for secretion of CTLA4-Ig by flow cytometry as described below. Three independent MIN6 transfectants that constitutively produce similar amounts of CTLA4-Ig in vitro were selected. In the preliminary in vivo transplantation experiments (see below), these transfectants gave similar results. Transfectants were cultured for at least 2 months before transplantation. A MIN6 transfectant (CTLA4-Ig/MIN6) was selected and used in this study.

Detection of CTLA4-Ig in vitro by flow cytometry. B7.1-transfected P815 cells were incubated with culture supernatant from CTLA4-Ig-transfected or parental MIN6 cells for $1 \mathrm{~h}$, then washed, and incubated for $30 \mathrm{~min}$ with FITC-labelled polyclonal goat anti-human IgG (Cappel, Melvern, Pa., USA) diluted to 1:100. The cells were then washed and analysed on an EPICSXL flow cytometer (Coulter Electronics, Hialeah, Fla., USA).

Mixed lymphocyte reaction (MLR). Mesenteric lymph node cells from recipient mice $(\mathrm{C} 3 \mathrm{H} / \mathrm{Hej})$ suspended in complete RPMI 1640 medium $\left(5 \times 10^{5} /\right.$ well $)$ were cultured with the same number of $20-\mathrm{Gy} \gamma$-irradiated splenocytes in 96-well flat-bottom microtitre plates. Serial dilutions of CTLA4-Ig obtained from a COS7 transfectant or culture supernatant of MIN6 cells transfected with CTLA4-Ig were then added. After 4 days of culture, the cells were pulsed with [methyl- $\left.{ }^{3} \mathrm{H}\right]$-thymidine (TdR) (Amersham International, Buckinghamshire, UK) for $6 \mathrm{~h}(1.0 \mu \mathrm{Ci} /$ well $)$. The cells were then harvested onto glass fibre filters, and ${ }^{3} \mathrm{H}-\mathrm{TdR}$ uptake was measured in a liquid scintillation counter (Wallac, Turku, Finland).

Insulin secretion in vitro. The amount of insulin secreted in vitro by CTLA4-Ig-transfected or parental MIN6 cells was determined as previously described [19]. Briefly, cells $\left(5 \times 10^{5}\right)$ were plated onto six-well plates and grown in DMEM growth medium for 2 days. The cells were washed twice in DMEM containing $0.5 \mathrm{mmol} / \mathrm{l}$ glucose and $15 \%$ FCS and incubated for $1 \mathrm{~h}$. The medium was then replaced with fresh DMEM containing 5\% FCS and $0,5.6$, or $25 \mathrm{mmol} / \mathrm{l}$ glucose. The culture supernatants were collected after $12 \mathrm{~h}$ of incubation, spun to remove cell debris, and stored at $-20^{\circ} \mathrm{C}$. Samples were later analysed for insulin content using an insulin ELISA kit (Morinaga, Yokohama, Japan).

Transplantation of CTLA4-Ig transfectants. CTLA4-Ig-transfected or parental MIN6 cells $\left(1 \times 10^{6}\right)$ were transplanted subcu- taneously into the right flank of STZ-induced diabetic $\mathrm{C} 3 \mathrm{H} / \mathrm{Hej}$ mice. Spleen cells $\left(1 \times 10^{6}\right)$ from the donor strain $(\mathrm{C} 57 \mathrm{BL} / 6)$ were injected i.v. at the time of transplantation to accelerate the immune response to the MIN6 cells (DST). Some of the recipients were given i.p. injections of either an anti-CTLA4 monoclonal antibody (mAb) (UC10-4F10) [24], which was kindly given by Dr. J. A. Bluestone (Committee on Immunology, The University of Chicago, Chicago, Ill., USA) or a control hamster IgG mAb $(0.2 \mathrm{mg}$ on day 0 and $0.1 \mathrm{mg}$ on days $3,6,9,12$, and 15). The function of the graft was monitored by measuring the blood glucose concentration. Rejection was defined as a blood glucose concentration higher than $300 \mathrm{mg} / \mathrm{dl}$ in two consecutive measurements.

Determination of the serum level of CTLA4-Ig in recipients. Serum concentrations of CTLA4-Ig in mice were assayed by ELISA. Serum samples were collected periodically from the tail vein. Goat anti-human IgG $(10 \mu \mathrm{g} / \mathrm{ml}$ in PBS; preabsorbed with mouse IgG) (American Qualex, San Clemente, Calif, USA) was coated onto 96-well microplates $(50 \mu \mathrm{l} /$ well $)$ (Sumilon MS-8596F; Sumitomo Bakelite, Tokyo, Japan) at $4{ }^{\circ} \mathrm{C}$ overnight. The wells were then blocked with $3 \%$ bovine serum albumin in PBS for $2 \mathrm{~h}$. A test serum sample or standard CTLA4-Ig was added to each well and incubated for $30 \mathrm{~min}$. After washing, biotinylated hamster anti-mouse CTLA4 mAb $(1.0 \mu \mathrm{g} / \mathrm{ml}$; 1B8; Southern Biotechnology Associates, Birmingham, Al., USA) was added to each well and incubated for $30 \mathrm{~min}$. After washing, peroxidase-conjugated streptavidin ( $1 \mu \mathrm{g} / \mathrm{ml}$; Zymed, San Francisco, Calif., USA) was added. For detection, $O$-phenylenediamine $(0.4 \mathrm{mg} / \mathrm{ml} ; 50 \mu \mathrm{l} /$ well $)$ was added, and the chromogenic reaction was allowed to proceed for $10 \mathrm{~min}$ at room temperature. The reaction was stopped with $25 \mu \mathrm{l} 8 \mathrm{~N} \mathrm{H}_{2} \mathrm{SO}_{4}$, and the plates were then read at $490 \mathrm{~nm}$ in a microtitre plate reader (InterMed, Tokyo, Japan).

Immunohisitochemistry. For immunohistochemical analysis, MIN6 or CTLA4-Ig/MIN6 cells $\left(1 \times 10^{7}\right)$ were transplanted into STZ-induced diabetic $\mathrm{C} 3 \mathrm{H} / \mathrm{Hej}$ mice with or without DST. DST similarly induced acute rejection of MIN6 grafts under this condition. Grafts were harvested 8 days after transplantation. For detection of insulin in the graft, the paraffin sections were stained using the Histofine SAB-PO insulin kit (Nichirei, Tokyo, Japan). For detection of T cells, paraffin sections were pretreated with microwave-heating for $15 \mathrm{~min}$ and incubated with rabbit anti-CD3 antibody (1:100; DAKO, Copenhagen, Denmark) at $37^{\circ} \mathrm{C}$ for $60 \mathrm{~min}$ [25]. The sections were washed in PBS, and incubated with $4 \mu \mathrm{g} / \mathrm{ml}$ peroxidase conjugated anti-rabbit IgG (Nichirei) for $30 \mathrm{~min}$ at room temperature. Antibody binding was visualised using a Histofine SAB-PO kit (Nichirei) with diaminobenzidine as a substrate. The slides were counterstained with hematoxylin. For detection of MHC class I $\left(\mathrm{H}-2 \mathrm{~K}^{\mathrm{b}}\right)$, cryostat sections fixed in acetone were incubated with the biotin-conjugated anti-mouse $\mathrm{H}-2 \mathrm{~K}^{\mathrm{b}} \mathrm{mAb}$ ( $1 \mu \mathrm{g} / \mathrm{ml}$; AF6-88.5; Pharmingen, San Diego, Calif., USA) at $4{ }^{\circ} \mathrm{C}$ overnight. After washing with $\mathrm{PBS}$, the sections were incubated with peroxidase-conjugated streptavidin and diaminobenzidine as a substrate. Control tissue sections were incubated in the same way, with the first step omitted.

Detection of in situ production of CTLA4-Ig. Frozen sections were fixed with acetone and were incubated with $5 \mu \mathrm{g} / \mathrm{ml}$ goat anti-human IgG (American Qualex) for $2 \mathrm{~h}$. The sections were washed three times in PBS, and incubated with peroxidase-labelled rabbit anti-goat IgG (American Qualex) for $30 \mathrm{~min}$. Antibody binding was visualised using metal-enhanced diaminobenzidine (Pierce, Rockford, Ill., USA). The slides were counterstained with Giemsa solution. 
A

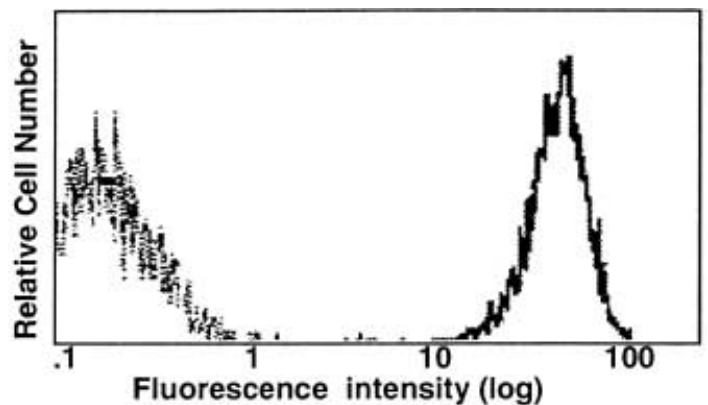

B

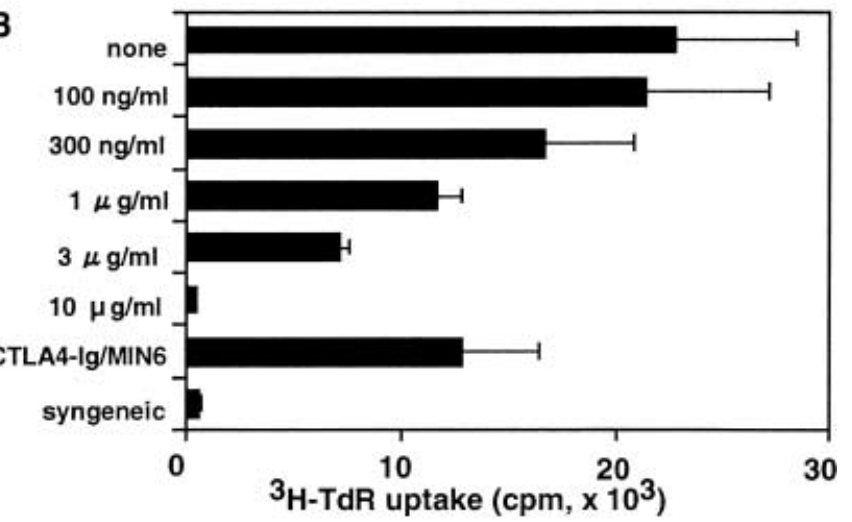

C

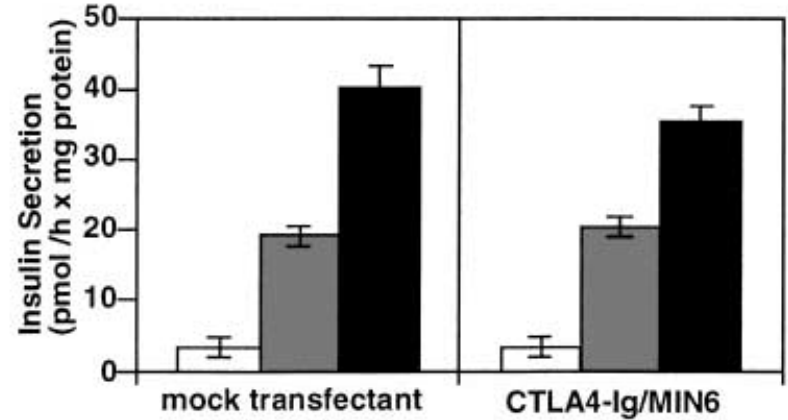

Fig. 1A-C. Production of functional CTLA4-Ig and regulated insulin secretion in CTLA4-Ig/MIN6 cells. A Recombinant CTLA4-Ig bound to B7-expressing cells (dotted line: supernatant from MIN6; solid line: supernatant from CTLA4Ig/MIN6). B Recombinant CTLA4-Ig inhibited the allogeneic MLR in a dose-dependent manner. Lymphocytes from recipient mice $(\mathrm{C} 3 \mathrm{H} / \mathrm{Hej})$ were incubated with irradiated stimulator splenocytes and supernatant from CTLA4-Ig/MIN6 (final dilution: $25 \%$ ) or serial dilutions of purified CTLA4-Ig for 4 days in triplicate wells. After a 6-h pulse of $1.0 \mu \mathrm{Ci}$ of $\left[{ }^{3} \mathrm{H}\right]-\mathrm{TdR}$, lymphocyte proliferation was measured as ${ }^{3} \mathrm{H}$ uptake $(\mathrm{cpm})$. Culture supernatant of CTLA4-Ig/MIN6 cells containing $2.2 \mu \mathrm{g} / \mathrm{ml}$ CTLA4-Ig was used in this experiment. Similar results were obtained in two independent experiments. C Insulin secretion by CTLA4-Ig/MIN6 cells. Mock transfected or CTLA4-Ig/MIN6 cells were preincubated in medium containing $0.5 \mathrm{mmol} / \mathrm{l}$ glucose for $1 \mathrm{~h}$ and further incubated in medium containing 5\% FCS and open bars 0, shaded bars 5.6, or solid bars $25 \mathrm{mmol} / \mathrm{l}$ glucose for $12 \mathrm{~h}$. The culture supernatants were collected and assayed for insulin content. Results obtained from one of the two independent experiments were shown
A

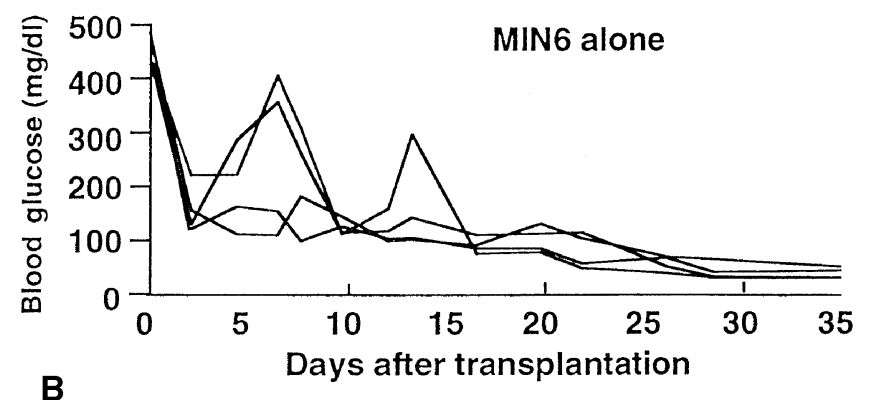

B

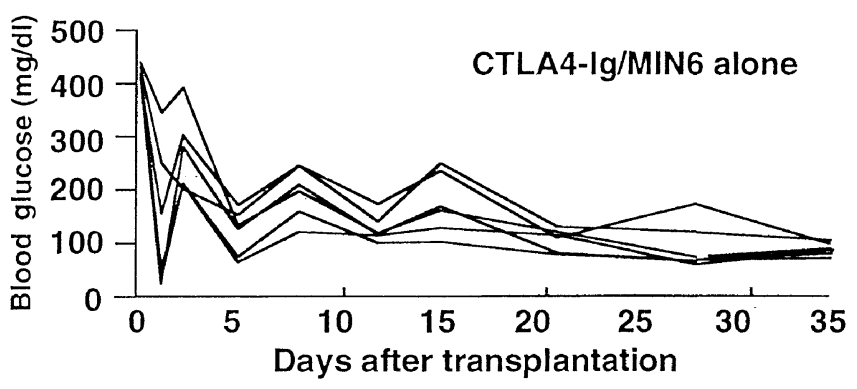

C

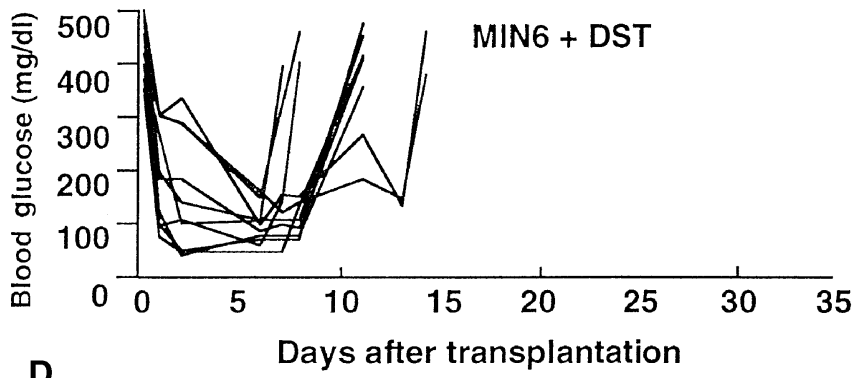

D

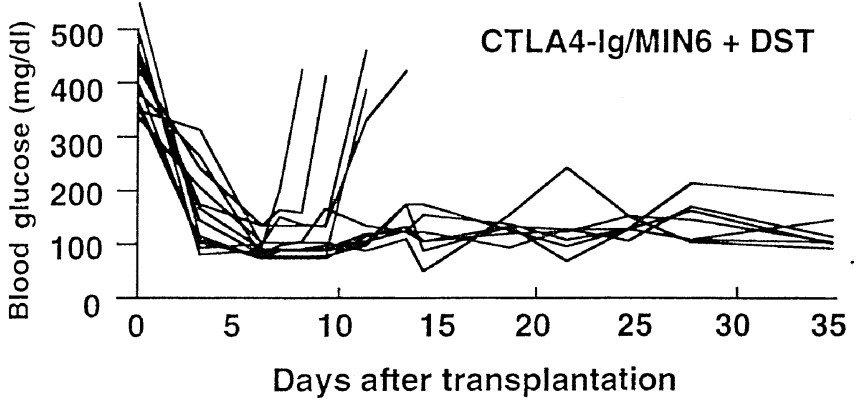

Fig. 2A-D. Blood glucose concentrations of animals given MIN6 or CTLA4-Ig/MIN6 with or without simultaneous DST. MIN6 cells (A: $n=4)$ or CTLA4-Ig/MIN6 cells (B: $n=6)$ were transplanted $\left(1 \times 10^{6}\right.$ cells) into the lateral flank of STZinduced diabetic $\mathrm{C} 3 \mathrm{H} / \mathrm{Hej}$ mice without DST. MIN6 cells (C: $n=10)$ or CTLA4-Ig/MIN6 cells (D: $n=12)$ were transplanted similarly but with DST $\left(1 \times 10^{6}\right.$ splenocytes $)$. MIN6 cells and CTLA4-Ig/MIN6 cells survived in non-sensitised diabetic $\mathrm{C} 3 \mathrm{H} / \mathrm{Hej}$ mice and restored euglycaemia (A, B)

Simultaneous grafting of CTLA4-Ig transfectants and parental MIN6 cells. CTLA4-Ig-transfected and parental MIN6 cells $\left(1 \times 10^{6}\right)$ were transplanted separately into the right and left flanks of STZ-induced diabetic C3H/Hej mice ( $n=17)$. In control mice, only MIN6 cells were transplanted. In both groups, spleen cells $\left(1 \times 10^{6}\right)$ from the donor strain $(\mathrm{C} 57 \mathrm{BL} / 6)$ were injected i.v. at the time of transplantation. On day 21 after transplantation, survival of the grafted MIN6 cells in both groups 
Insulin
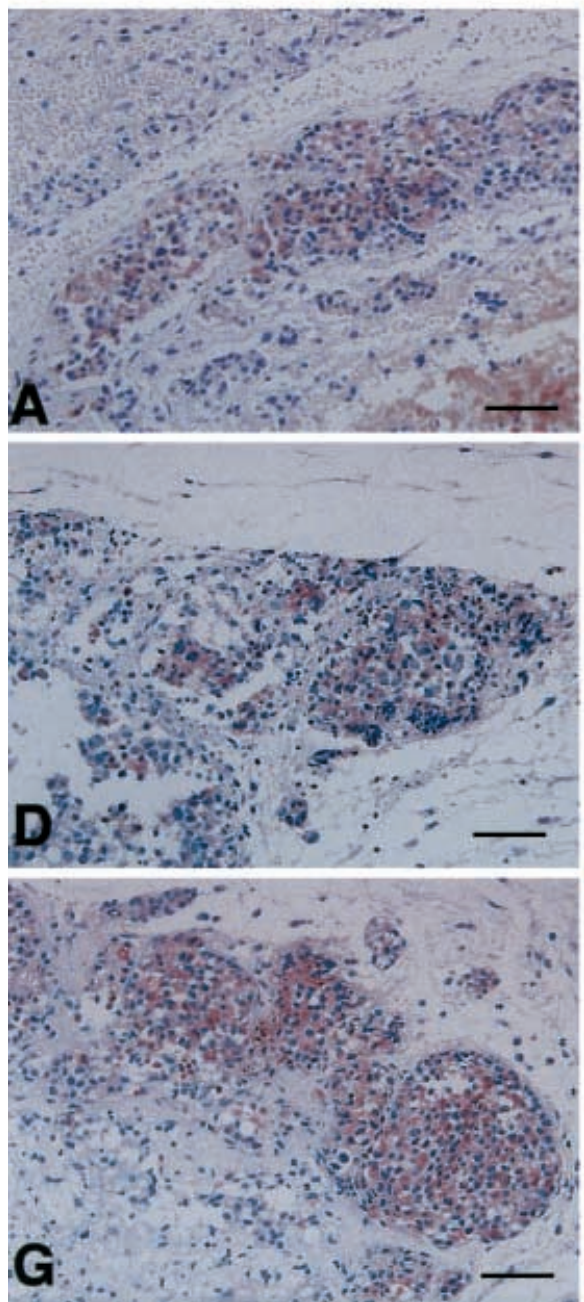

CD3
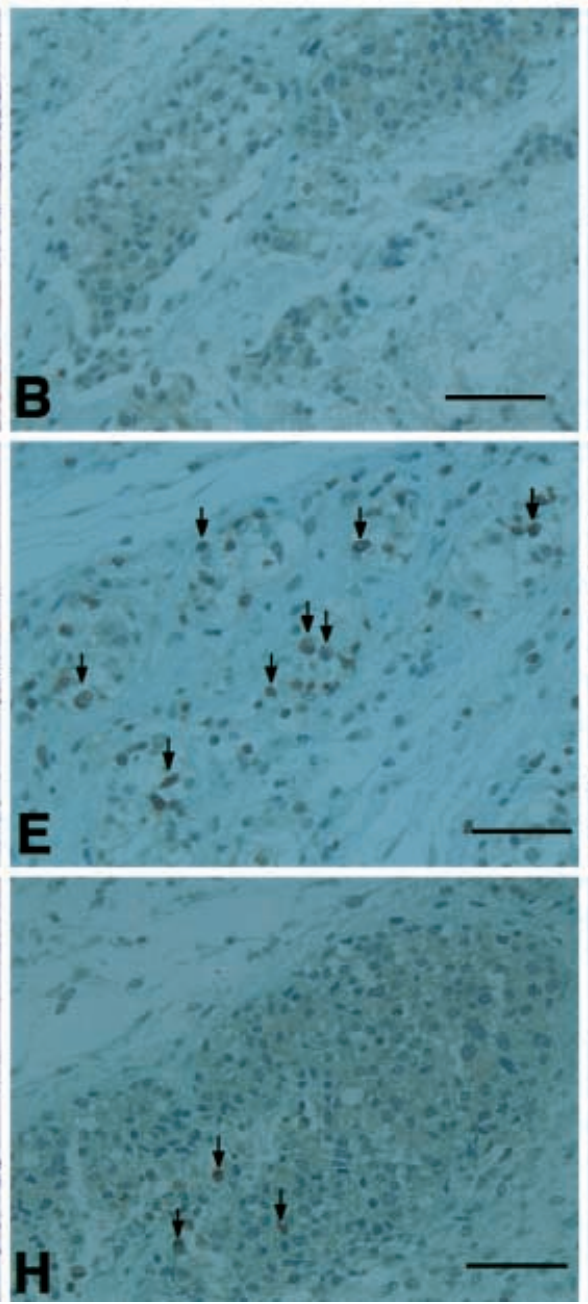

MHC class I
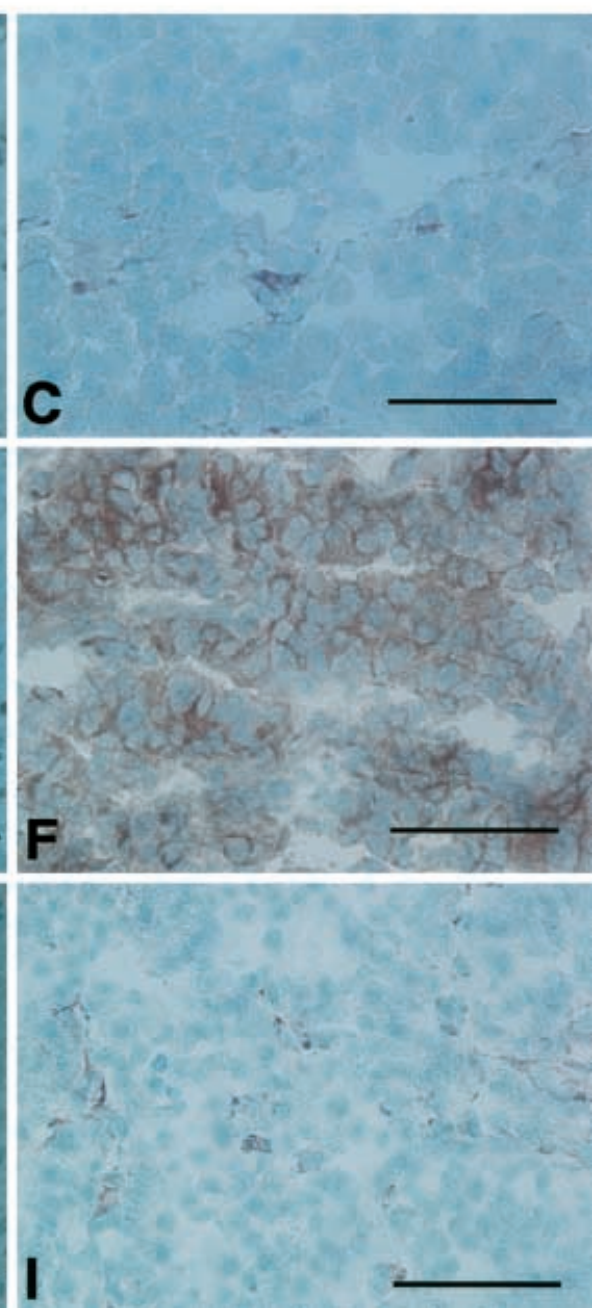

Fig. 3A-I. The histological appearance of subcutaneously transplanted MIN6 or CTLA4-Ig/MIN6 cells with or without DST treatment. MIN6 cells (A-F) or CTLA4-Ig/MIN6 cells (G-I) $\left(1 \times 10^{7}\right)$ were transplanted into STZ-induced diabetic C3H/Hej mice with (D-I) or without DST (A-C). Grafts were dissected 8 days after transplantation. Paraffin-embedded tissue sections were stained with anti-insulin antibody (A, D and $\mathbf{G})$ or anti-CD3 antibody $(\mathbf{B}, \mathbf{E}$ and $\mathbf{H})$. Frozen sections were stained with anti-MHC class I $\left(\mathrm{H}-2 \mathrm{~K}^{\mathrm{b}}\right) \mathrm{mAb}(\mathbf{C}, \mathbf{F}$ and $\mathbf{I}) . A r$ rows indicate $\mathrm{CD}^{+}$cells infiltrated into MIN6 or CTLA4Ig/MIN6 grafts. Scales bars, $50 \mu \mathrm{m}$

was determined macroscopically. In mice given a simultaneous transplantation of CTLA4-Ig/MIN6 and MIN6 cells, rejection of MIN6 cells was further confirmed by the presence of hyperglycaemia after surgical removal of the visible CTLA4Ig/MIN6 graft.

Statistical analysis. Data were expressed as the means \pm the SD. Graft survival in different experimental groups was compared using the log-rank test. Student's $t$ test was used for the comparison of paired and unpaired measurements. A $p$ value of less than 0.05 was considered to be statistically significant. All statistical calculations were performed using Statview-J5.0 for Macintosh system 8.6 software.

\section{Results}

Transfected MIN6 cells secreted functional CTLA4Ig. MIN6 cells were transfected with pCXN-CTLA4Ig to generate stable transformants. After G418 selection, transformants were examined for CTLA4-Ig production. The culture supernatant of a stable transformant cell line (CTLA4-Ig/MIN6) contained CTLA4Ig that was specifically reactive with B7.1-expressing cells (Fig. 1A). Purified CTLA4-Ig inhibited the MLR with an IC50 of $1 \mu \mathrm{g} / \mathrm{ml}$. Supernatant from CTLA4Ig/MIN6 also inhibited the MLR to $58 \%$ of control levels when it was diluted to $25 \%$ (Fig. 1B). Upon glucose loading, CTLA4-Ig/MIN6 cells showed increased insulin secretion in a dose-dependent manner, similar to original MIN6 or mock cells. Taken together, these results indicate that the CTLA4-Ig/MIN6 cells constitutively produced CTLA4-Ig and were capable of secreting insulin in response to high extracellular glucose (Fig. 1C).

Locally expressed CTLA4-Ig prolonged the survival of MIN6 cells in a model of DST-induced transplantation 
Table 1. Effect of anti-CTLA4 mAb on prolongation of graft survival by CTLA4-Ig

\begin{tabular}{|c|c|c|c|c|c|}
\hline Group & Graft and Treatment & $n$ & Graft survival (days) & $\mathrm{MST} \pm \mathrm{SD}$ (days) & $p^{\mathrm{a}}$ \\
\hline \multicolumn{6}{|l|}{ Exp. 1} \\
\hline 1 & CTLA4-Ig/MIN6 + DST & 4 & $22,>40 \times 3$ & $>35.5 \pm 9.0$ & \\
\hline 2 & CTLA4-Ig/MIN6 + DST+ control mAb & 4 & $24,>40 \times 3$ & $>36.0 \pm 8.0$ & NS vs 1 \\
\hline 3 & CTLA4-Ig/MIN6+DST+anti-CTLA4 mAb & 4 & $12,17,17,>40$ & $21.5 \pm 12.6$ & 0.029 vs $1,2, \mathrm{NS}$ vs 4 \\
\hline 4 & MIN6+DST & 4 & $12,22,22,24$ & $20.5 \pm 5.4$ & 0.041 vs $1,0.018$ vs 2 \\
\hline 1 & MIN6 alone & 3 & $>26 \times 3$ & $>26 \pm 0$ & \\
\hline 2 & MIN6 + anti-CTLA4 mAb & 5 & $>26 \times 5$ & $>26 \pm 0$ & \\
\hline 3 & MIN6+DST & 5 & $17,19,19,21,23$ & $19.8 \pm 2.3$ & \\
\hline 4 & MIN6+DST+anti-CTLA4 mAb & 5 & $15,15,19,21,21$ & $18.2 \pm 3.0$ & NS vs 3 \\
\hline
\end{tabular}

a Determined by the log rank test

CTLA4-Ig/MIN6 or parental MIN6 cells $\left(1 \times 10^{6}\right)$ were transplanted into STZ-induced diabetic $\mathrm{C} 3 \mathrm{H} / \mathrm{Hej}(\mathrm{H}-2 \mathrm{k})$ mice with simultaneous DST $\left(1 \times 10^{6}\right.$ splenocytes $)$. Some of the recipients were given i.p. injections of either anti-CTLA4 mAb or control hamster $\operatorname{IgG} \mathrm{mAb}(0.2 \mathrm{mg}$ on day 0 and $0.1 \mathrm{mg}$ on days $3,6,9$, 12 , and 15). Graft survival was monitored by blood glucose concentrations, and rejection was defined as a glucose concentration of $>300 \mathrm{mg} / \mathrm{dl}$ in two consecutive measurements rejection. When $1 \times 10^{6}$ MIN6 cells of C57BL/6 origin or CTLA4-Ig/MIN6 cells were transplanted into the flank of STZ-induced diabetic $\mathrm{C} 3 \mathrm{H} / \mathrm{Hej}$ recipients, most of the animals showed restored euglycaemia $(<200 \mathrm{mg} / \mathrm{dl})$ within 1 week post-transplantation and maintained it for more than 1 month (Fig. 2A, B). As we previously demonstrated [5], DST of spleen cells accelerated the host immune response, providing a model of pancreatic beta-cell transplantation rejection that is relevant to clinical settings where graft rejection is initiated by contaminating immunogenic nonislet cell populations. Whereas parental MIN6 cells of C57BL/6 origin survived in non-sensitised diabetic $\mathrm{C} 3 \mathrm{H} / \mathrm{Hej}$ mice and restored euglycaemia, the same cells were acutely rejected when DST was given to the recipient animals simultaneously (MST was 10.7 \pm 2.2 days) (Fig. 2C). Histologically, the MIN6 graft showed a minimum level of cellular infiltration by $\mathrm{T}$ cells, and was positively stained for insulin (Fig. 3A, B). Following DST, the MIN6 graft showed obvious signs of rejection with infiltration of $\mathrm{CD}^{+} \mathrm{T}$ cells (Fig. 3E). Both $\mathrm{CD}^{+}{ }^{+}$and $\mathrm{CD}^{+}{ }^{+} \mathrm{T}$ cell subsets were almost equally observed in the MIN6 graft (data not shown). Importantly, while the MIN6 graft expresses only marginal levels of MHC class I before DST (Fig. 3C), it came to express MHC class I abundantly after DST (Fig. 3F). The rejecting MIN6 graft was stained only weakly for insulin after DST (Fig. 3D). These results indicate that MIN6 cells, like purified murine islet beta cells, are only weakly immunogenic, but can be rejected by recipient mice by the concomitant sensitisation with immunogenic donor cells.

To determine whether this rejection can be circumvented by local expression of CTLA4-Ig, CTLA4Ig/MIN6 cells were transplanted into diabetic $\mathrm{C} 3 \mathrm{H} / \mathrm{Hej}$ mice sensitised with DST at the time of grafting. As shown in Fig. 2D, 7 of 12 CTLA4Ig/MIN6 grafts survived beyond day 20 after transplantation in allogeneic diabetic $\mathrm{C} 3 \mathrm{H} / \mathrm{Hej}$ mice given simultaneous DST, whereas none of the grafts of parental MIN6 cells survived beyond this time point in DST-sensitised mice. Histologically, the CTLA4Ig/MIN6 grafts showed little sign of tissue injury with only slight cellular infiltration even after DST (Fig. 3H), and no marked increase in MHC class I antigen expression (Fig. 3I). The overall survival of the CTLA4-Ig/MIN6 cells (MST was $>24.8 \pm 12.7$ days) was significantly prolonged compared with that of parental MIN6 cells (MST was 10.7 \pm 2.2 days). These results indicate that, under our experimental conditions, the forced expression of CTLA4-Ig can successfully suppress the accelerated rejection response induced by DST.

To ascertain whether the prolonged survival was attributable to CTLA4-Ig produced locally by the MIN6 transfectants, the effects of a neutralising anti-CTLA4 $\mathrm{mAb}$ were examined. As shown in Table 1, i.p. administration of the anti-CTLA4 mAb, but not an isotypematched control $\mathrm{mAb}$, induced prompt rejection of the CTLA4-Ig/MIN6 cells. When the subcutaneously inoculated CTLA4-Ig transfected cells were removed from normoglycaemic mice, blood glucose concentrations increased to over $300 \mathrm{mg} / \mathrm{dl}$ within 2 days, indicating that the transfected MIN6 cells were responsible for maintaining the normal blood glucose concentrations. In separate experiments, we also tested the effects of anti-CTLA4 mAb on the survival of parental MIN6 cells. While previous studies reported that administration of neutralising anti-CTLA4 mAb enhances T-cell responses by blocking inhibitory functions of CTLA4 [24], we found that the anti-CTLA4 $\mathrm{mAb}$ treatment did not affect survival of the parental MIN6 graft in either untreated- or DST-sensitised re- 
Table 2. Effect of contralateral transplantation of CTLA4-Ig/MIN6 on MIN6 survival at a remote site. In group 1, MIN6 cells $\left(1 \times 10^{6}\right)$ alone were transplanted into the right flank of STZ-induced diabetic C3H/Hej mice $(n=5)$

\begin{tabular}{llll}
\hline Group & Graft & Duration of normoglycaemia & $\begin{array}{l}\text { Number of MIN6 } \\
\text { graft surviving on day } 21\end{array}$ \\
\hline 1 & MIN6 alone (right) & $11,17,19,21,>21$ & $1 / 5$ \\
2 & MIN6 (right)+CTLA4-Ig/MIN6 (left) & $11 \times 2,14 \times 2,17,21>21 \times 4,>21 \times 6^{\mathrm{a}}$ & $0 / 6^{\mathrm{a}}$ \\
\hline
\end{tabular}

a Normoglycaemic mice bearing a visible CTLA4-Ig/MIN6 graft but no visible MIN6 graft

In Group 2, CTLA4-Ig/MIN6 $\left(1 \times 10^{6}\right)$ and parental MIN6 cells $\left(1 \times 10^{6}\right)$ were transplanted separately into each flank of STZinduced diabetic $\mathrm{C} 3 \mathrm{H} / \mathrm{Hej}$ mice $(n=17)$. In both groups, spleen cells $\left(1 \times 10^{6}\right)$ from the donor strain $(\mathrm{C} 57 \mathrm{BL} / 6)$ were in- jected i.v. at the time of transplantation. The survival of the parental MIN6 cells was examined on day 21 after transplantation, when only one out of five control animals (Group 1) showed normoglycaemia. At this time point, none of the animals in Group 2 showed a recognisable MIN6 graft

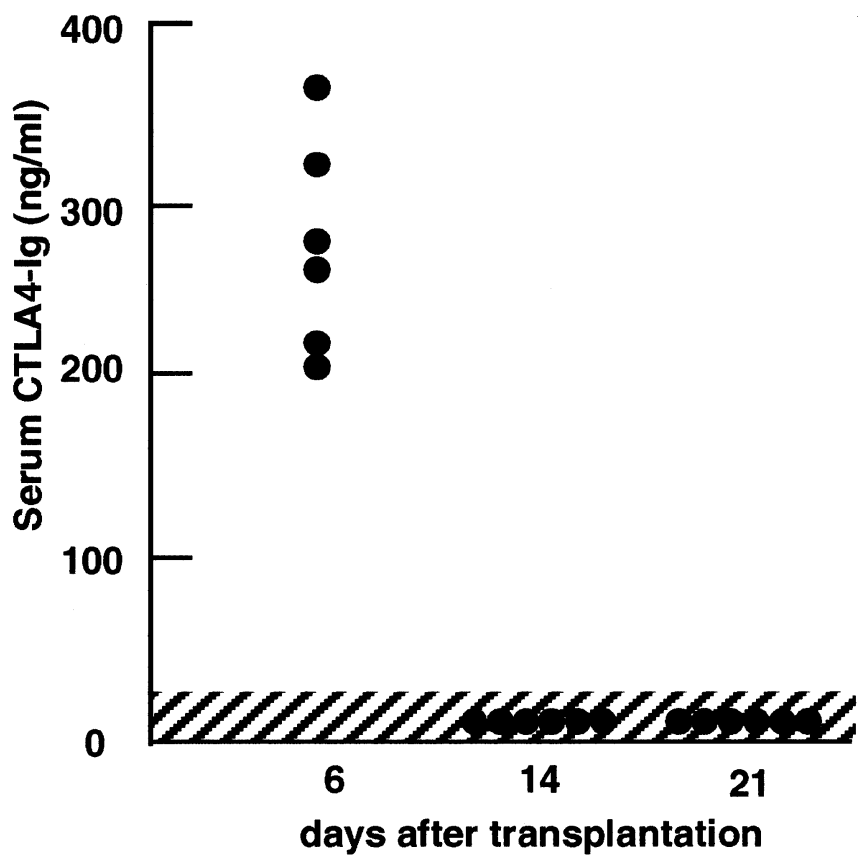

Fig. 4. CTLA4-Ig concentrations in the peripheral blood of mice transplanted with CTLA4-Ig/MIN6 cells. CTLA4Ig/MIN6 cells $\left(1 \times 10^{6}\right)$ were subcutaneously transplanted into STZ-induced diabetic C3H/Hej mice. Mouse serum samples were collected from CTLA4-Ig/MIN6-transplanted, euglycaemic mice at 6,14 , and 21 days after transplantation. Concentrations of CTLA4-Ig were determined by ELISA. The shaded zone indicates the range where CTLA4-Ig concentrations were below the detection level $(3 \mathrm{ng} / \mathrm{ml})$

(Fig. 4), indicating that CTLA4-Ig was present systemically during an early stage after transplantation but disappeared thereafter from the circulation. When in situ CTLA4-Ig production was examined by immunohistochemistry, a strong signal was observed within and around the engrafted CTLA4-Ig/MIN6 cells at 72 days after transplantation (Fig. 5). These results suggest that the prolonged survival of CTLA4Ig/MIN6 cells was associated with the continued presence of CTLA4-Ig in situ, and that its protective effect was conferred locally. 


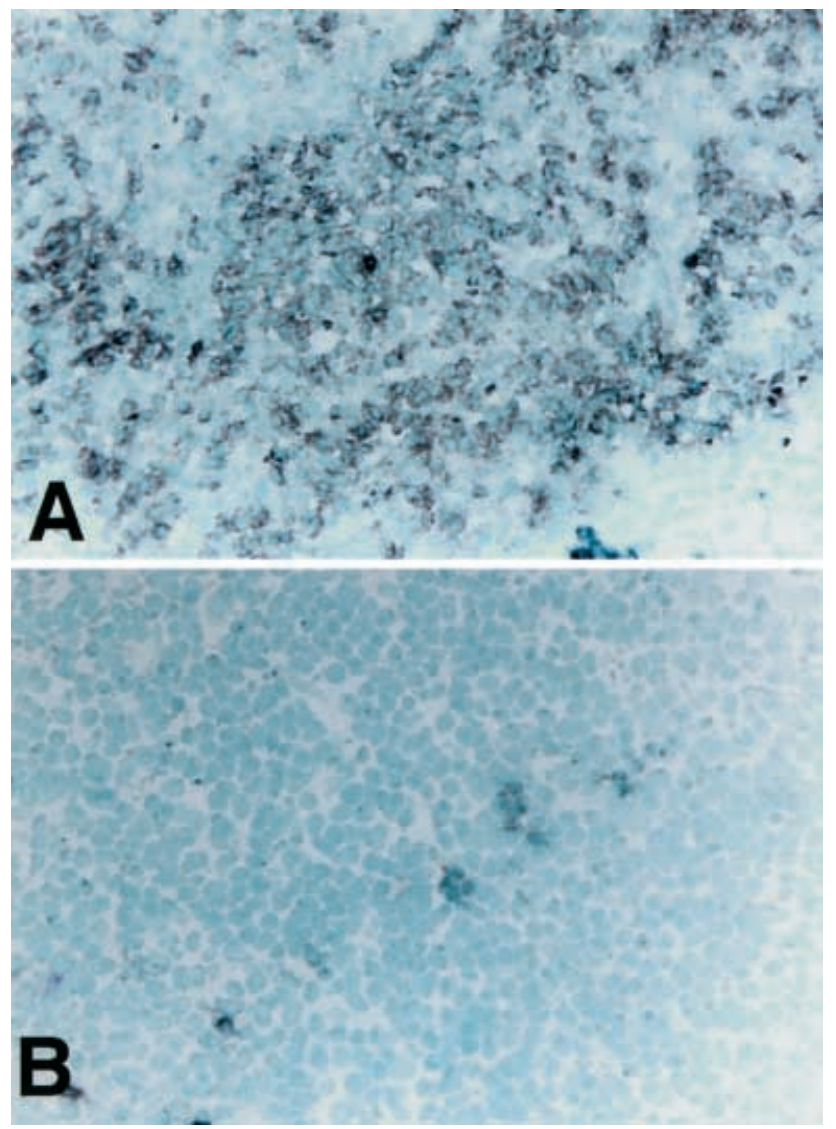

Fig. 5A,B. Long-term production of CTLA4-Ig by a CTLA4Ig/MIN6 graft in situ. Cryostat sections were made from a CTLA4-Ig/MIN6 graft 72 days after transplantation with simultaneous DST (A) and a MIN6 graft 20 days after transplantation without DST (B), and incubated with goat anti-human IgG to detect CTLA4-Ig. The sections were then stained with horseradish peroxidase-labelled anti-goat IgG. (original magnifications: $\times 50$ )

\section{Discussion}

Our study demonstrates that locally expressed CTLA4Ig in transplanted MIN6 cells significantly prolonged the survival of the beta cells in sensitised recipient mice. Administration of a high dose of CTLA4-Ig was previously reported to suppress immune responses systemically $[14,15,16,17]$, and several preceding studies indicate that local delivery of CTLA4-Ig prolongs the survival of islet allografts in mice $[8,9,18]$. Using adenovirus-mediated expression of CTLA4-Ig, investigators [26] recently reported that the production of CTLA4-Ig by islet cells themselves, but not by cells located in remote sites, is effective in prolonging islet allograft survival. Another study [27] showed that ex vivo "coating" of islet allografts with CTLA4-Ig protein before transplantation resulted in a long-term engraftment of the islet allografts. However, little has been known about mechanisms involved in the prolongation of allograft survival in sensitised animals by locally delivered CTLA4-Ig in vivo.
To investigate this issue, we transplanted CTLA4Ig/MIN6 cells and MIN6 cells separately into each flank of antigen-sensitised diabetic $\mathrm{C} 3 \mathrm{H} / \mathrm{Hej}$ mice, and examined the survival of the allografts. The results showed that locally expressed CTLA4-Ig prolonged the survival of the CTLA4-Ig/MIN6 cells, but not of the MIN6 cells at a remote site, suggesting that the protective effect of the CTLA4-Ig was conferred locally. In addition, we found that the prolonged survival of CTLA4-Ig/MIN6 allografts was closely associated with the continued production of CTLA4-Ig in situ, but not with its presence in the systemic circulation. Immunohistochemical analysis confirmed that the surviving CTLA4-Ig/MIN6 allografts continued to produce CTLA4-Ig in situ more than 70 days after transplantation (Fig. 5). In contrast, serum CTLA4-Ig was detectable on day 6 (mean $268 \pm 66 \mathrm{ng} / \mathrm{ml}$ ), but not on days 14 and 21 in the CTLA4-Ig/MIN6-engrafted mice. (The minimum detection level of the assay used was $3 \mathrm{ng} / \mathrm{ml}$.) The level of CTLA4-Ig detected in the peripheral blood was presumably insufficient to suppress the host T-cell response systemically, because our in vitro studies showed that higher concentrations of CTLA4-Ig are required to suppress the anti-alloantigen T-cell responses (Fig. 1B). In support of this notion, mice engrafted with CTLA4-Ig/MIN6 cells showed almost normal T-cell responses to alloantigen in vitro and rejected a donor type skin graft in a first set fashion (data not shown). Taken together, these results suggest that the locally produced CTLA4-Ig by MIN6 cells did not induce systemic antigen-specific unresponsiveness, but rather provided a local microenvironment that facilitated the survival of the engrafted MIN6 cells.

An immunosuppressive effect of the locally produced CTLA4-Ig could be exerted in steps, as follows. First, secreted CTLA4-Ig could help abrogate the initial T-cell responses by interrupting the CD28-B7-dependent co-stimulatory signals. The CTLA4-Ig/MIN6 cells are devoid of B7 antigen expression; therefore, $\mathrm{B}^{+}$APCs need to be recruited to the graft site for a CD28-B7-mediated rejection response to take place. Locally produced CTLA4-Ig could suppress the initial T-helper responses by inhibiting the co-stimulatory signals provided by B7+ APCs. Second, locally expressed CTLA4-Ig could help down-regulate the immunogenicity of MIN6 cells. While unstimulated MIN6 cells were poorly immunogenic and could not be recognized by unprimed allogeneic $\mathrm{C} 3 \mathrm{H} / \mathrm{Hej}$ mice (Fig. 2A), they were rapidly rejected upon simultaneous DST (Fig. 2C). This indicates that MIN6 cells are vulnerable to immunological attack once an accelerated rejection response is generated. While the MIN6 cells barely express MHC class I in unsensitised mice, they express MHC class I abundantly in mice given DST. In sharp contrast, CTLA4-Ig/MIN6 cells did not express readily detectable amounts of MHC class I antigen expression even after DST. 
Therefore, by blocking the co-stimulatory signals of B7+ APCs locally, CTLA4-Ig may inhibit production of cytokines, such as TNF $\alpha$ and IFN- $\gamma$, that can upregulate MHC expression in MIN6 cells [19].

Although our results suggest that CTLA4-Ig expressed in MIN6 cells prolonged the graft survival via local mechanisms, it is also possible that secreted CTLA4-Ig could affect T-cell functions in the draining lymph nodes, where the immune responses to MIN6 grafts is probably initiated. Because CTLA4-Ig was detected in the circulation during an early stage after transplantation in this study, secreted CTLA4-Ig could affect immune responses in the lymph nodes at this time point. We previously showed that DST induces production of various cytokines and donor microchimerism in lymphoid tissues [28]. Accordingly, it is possible that secreted CTLA4-Ig could modulate DSTinduced immune response to alloantigens in lymph nodes during an early stage after transplantation. To gain a better understanding of mechanisms underlying site-specific effects of CTLA4-Ig produced by transfected MIN6 cells, it is necessary in future to examine cytokine production and T-cell responses against alloantigens in lymphoid tissues including draining lymph nodes at various time points after transplantation.

Although the local expression of CTLA4-Ig in MIN6 cells appeared to be advantageous for their survival, graft rejection was still observed in some recipient mice. There are several possible reasons for the different responses of these mice. For instance, it is now evident that the co-stimulatory signals for T-cells are redundant and that several ligand and receptor pairs including the CD40/CD40 ligand pathway are involved in T-cell activation [29]. Therefore, blockage of the CD28-dependent co-stimulatory signals by CTLA4-Ig alone might not have been sufficient for the complete suppression of $\mathrm{T}$ cells. In addition, in the rejected grafts, it is conceivable that the production of CTLA4-Ig was not sufficient to override the accelerated rejection response induced by DST. While we used stably transfected MIN6 cells to produce CTLA4-Ig, the rate at which the CTLA4-Ig is produced in individual grafts in vivo could be affected by their local environment in situ. In addition, the immunogenicity of the human-Ig-based chimeric CTLA4 protein used in this study could have played a role in the outcome. In fact, we found anti-human IgG activity in the serum samples of mice engrafted with CTLA4-Ig/MIN6 cells (data not shown), which could have reduced the efficacy of the CTLA4-Ig. CTLA4-Ig with mouse Fc could be more suitable for inhibiting CD28-dependent co-stimulatory signals in mice.

While we found that locally expressed CTLA4-Ig significantly suppressed the acute rejection response induced by DST, a study [30] reported that the i.p. administration of CTLA4-Ig failed to prolong the allograft survival in mice given DST. Differences in the route of CTLA4-Ig delivery, timing of the DST, or combinations of mouse strains used or both could have contributed to this apparent discrepancy in results.

Under most clinical settings for islet transplantation, which involves simultaneous organ transplantation or islet transplantation from multiple donors sharing MHC antigens, the purified islets might be injured by the systemic anti-donor immune response elicited by the donor antigens. Our results demonstrate that local expression of CTLA4-Ig by the genetically engineered pancreatic beta-cell line MIN6 successfully circumvented the accelerated rejection responses induced by DST, and significantly prolonged the allograft survival in vivo, suggesting that the targeted delivery of CTLA4-Ig could protect the graft without causing systemic immunosuppression. Together with technical advances in targeted gene delivery, precise site-directed immunosuppression could become an important strategy in clinical islet transplantation.

Acknowledgements. This work was partly supported by the Grants from Japanese Ministry of Education, Culture, and Science.

\section{References}

1. Gruessner A, Sutherland DE (1994) Pancreas transplant results in the United Network for Organ Sharing (UNOS) United States of America (USA) Registry compared with non-USA data in the International Registry. In: Terasaki PI, Cecka JM (eds) Clinical transplants. UCLA Tissue Typing Laboratory, Los Angeles, pp 47-68

2. Hering BJ, Browatzki CC, Schultz A et al. (1993) Clinical islet transplantation-registry report, accomplishments in the past and future research needs. Cell Transplant 2:269-282

3. Shapiro AM, Lakey JR, Ryan EA et al. (2000) Islet transplantation in seven patients with type 1 diabetes mellitus using a glucocorticoid-free immunosuppressive regimen. $\mathrm{N}$ Engl J Med 343:230-238

4. Bowen KM, Prowse SJ, Lafferty KJ (1981) Reversal diabetes by islet transplantation: vulnerability of the established allograft. Science 213:1261-1262

5. Gotoh M, Maki T, Satomi S, Porter J, Monaco AP (1986) Immunological characteristics of purified pancreatic islet grafts. Transplantation 42:387-390

6. Takeda Y, Gotoh M, Dono K et al. (1998) Protection of islet allografts transplanted together with Fas ligand expressing testicular allografts. Diabetologia 41:315-321

7. Lau HT, Yu M, Fontana A, Stoeckert CJ Jr (1996) Prevention of islet allograft rejection with engineered myoblasts expressing FasL in mice. Science 273:109-112

8. Gainer AL, Korbutt GS, Rajotte RV, Warnock GL, Elliott JF (1997) Expression of CTLA4-Ig by biolistically transfected mouse islets promotes islet allograft survival. Transplantation 63:1017-1021

9. Olthoff KM, Judge TA, Gelman AE et al. (1998) Adenovirus-mediated gene transfer into cold-preserved liver allografts: survival pattern and unresponsiveness following transduction with CTLA4Ig. Nat Med 4:194-200

10. Isobe M, Yagita H, Okumura K, Ihara A (1992) Specific acceptance of cardiac allograft after treatment with antibodies to ICAM-1 and LFA-1. Science 255:1125-1127 
11. Qin BL, Chavin KD, Lin J, Yagita H, Bromberg JS (1994) Anti-CD2 receptor and anti-CD2 ligand (CD48) antibodies synergize to prolong allograft survival. J Exp Med 179: 341-346

12. June CH, Bluestone JA, Nadler LM, Thompson CB (1994) The B7 and CD28 receptor families. Immunol Today 15:321-331

13. Linsley PS, Brady W, Urnes M, Grosmaire LS, Damle NK, Ledbetter JA (1991) CTLA-4 is a second receptor for the B cell activation antigen B7. J Exp Med 174:561-569

14. Linsley PS, Wallace PM, Johnson J et al. (1992) Immunosuppression in vivo by a soluble form of the CTLA-4T cell activation molecule. Science 257:792-795

15. Lenschow DJ, Zeng Y, Thistlethwaite JR et al. (1992) Long-term survival of xenogeneic pancreatic islet grafts induced by CTLA4lg. Science 257:789-792

16. Turka LA, Linsley PS, Lin H et al. (1992) T-cell activation by the CD28 ligand B7 is required for cardiac allograft rejection in vivo. Proc Natl Acad Sci USA 89:1110211105

17. Pearson TC, Alexander DZ, Winn KJ, Linsley PS, Lowry RP, Larsen CP (1994) Transplantation tolerance induced by CTLA4-Ig. Transplantation 57:1701-1706

18. Chahine AA, Yu M, McKernan MM, Stoeckert C, Lau HT (1995) Immunomodulation of pancreatic islet allografts in mice with CTLA4Ig secreting muscle cells. Transplantation 59:1313-1318

19. Miyazaki J, Araki K, Yamato E et al. (1990) Establishment of a pancreatic beta cell line that retains glucose-inducible insulin secretion: special reference to expression of glucose transporter isoforms. Endocrinology 127:126-132

20. Nakajima A, Azuma M, Kodera S et al. (1995) Preferential dependence of autoantibody production in murine lupus on CD86 costimulatory molecule. Eur J Immunol 25:30603069
21. Yamada A, Murakami M, Ijima K et al. (1996) Long-term acceptance of major histocompatibility complex-mismatched cardiac allograft induced by a low dose of CTLA4IgM plus FK506. Microbiol Immunol 40:513-518

22. Niwa H, Yamamura K, Miyazaki J (1991) Efficient selection for high-expression transfectants with a novel eukaryotic vector. Gene 108:193-200

23. Sompayrac LM, Danna KJ (1981) Efficient infection of monkey cells with DNA of simian virus 40. Proc Natl Acad Sci USA 78:7575-7578

24. Walunas TL, Lenschow DJ, Bakker CY et al. (1994) CTLA-4 can function as a negative regulator of T cell activation. Immunity 1:405-413

25. Mason DY, Cordell J, Brown M, et al. (1989) Detection of $\mathrm{T}$ cells in paraffin wax embedded tissue using against a peptide sequence from the CD3 antigen. J Clin Pathol 42: 1194-2000

26. Feng S, Quickel RR, Hollister-Lock J et al. (1999) Prolonged xenograft survival of islets infected with small doses of adenovirus expressing CTLA4Ig. Transplantation 67:1607-1613

27. Steurer W, Nickerson PW, Steele AW, Steiger J, Zheng XX, Strom TB (1995) Ex vivo coating of islet cell allografts with murine CTLA4/Fc promotes graft tolerance. J Immunol 155:1165-1174

28. Ota H, Gotoh M, Ohzato H et al. (1999) Microchimerism in thymus is associated with up-regulated $\mathrm{T}$ helper type 1 cytokine transcription during cardiac allograft rejection in rats. Transplantation 67:165-173

29. Durie FH, Foy TM, Masters SR, Laman JD, Noelle RJ (1994) The role of CD40 in the regulation of humoral and cell-mediated immunity. Immunol Today 15:406-411

30. Roy-Chaudhury P, Nickerson PW, Manfro RC et al. (1997) CTLA4Ig attenuates accelerated rejection (presensitization) in the mouse islet allograft model. Transplantation 64: 172-175 